\title{
A Laboratory Study on Pathogenic Fungi Carried by Flowers in an Infectious Disease Ward
}

\author{
Jun Liu ${ }^{1}$, Yu Wang ${ }^{1}$, Liping Zhu ${ }^{2}$, Qiangqiang Zhang ${ }^{3}$, Wenhong Zhang ${ }^{2}$ and Lingyun Shao ${ }^{2^{*}}$ \\ ${ }^{1}$ Department of Nursing, Huashan Hospital, Fudan University, Shanghai, China \\ ${ }^{2}$ Department of Infectious Diseases, Huashan Hospital, Fudan University, Shanghai, China \\ ${ }^{3}$ Department of Dermatology, Huashan Hospital, Fudan University, Shanghai, China
}

*Corresponding author: Lingyun Shao, Department of Infectious Diseases, Huashan Hospital, Fudan University, Shanghai, China, Tel: 86-21-52888262; Fax: 86-21-52888714; E-mail: lingyun26@fudan.edu.cn

Received date: August 14, 2014, Accepted date: September 16, 2014, Publication date: September 19, 2014

Copyright: ( 2014 Liu J, et al. This is an open-access article distributed under the terms of the Creative Commons Attribution License, which permits unrestricted use, distribution, and reproduction in any medium, provided the original author and source are credited.

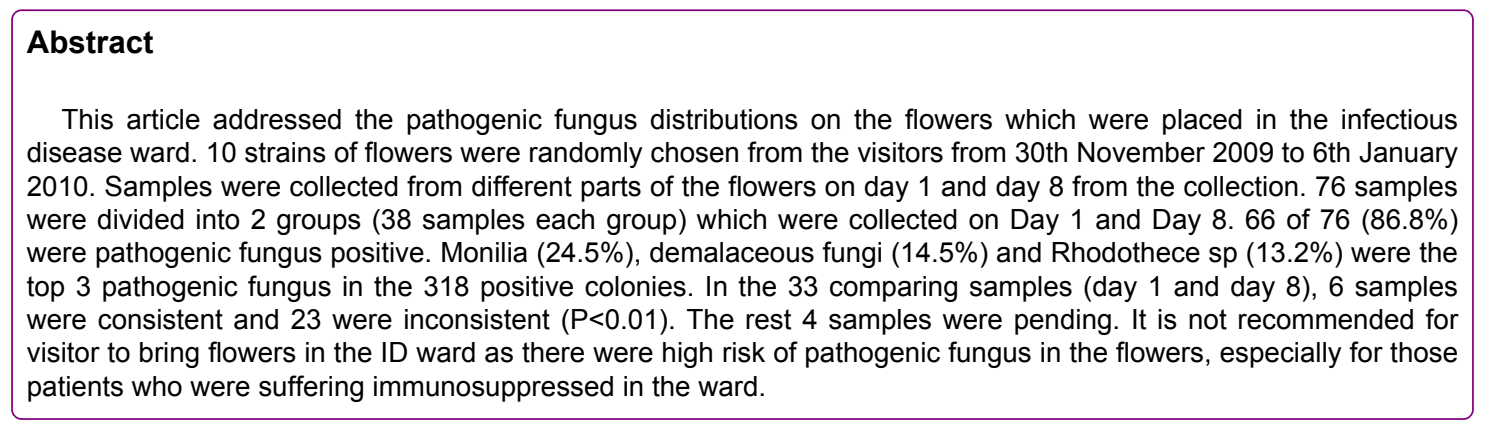

Keywords: Pathogenic Fungus, Flower, ID ward

\section{Introduction}

Flowers have ever been shown in studies to bring about a positive mood. It also brightened the room and served as a constant reminder of how much you care. Visitors always brought flowers when they visited patients in the hospital.

The flowers were placed to improve the environment in the hospital [1]. However, Tormo Molina insisted pathogens were found in the vase of flowers which was placed in the ward in the 1970s. The flowers may be contaminated with variety of pathogenic and non-pathogenic microorganisms during the time of growing and transporting [2-5]. When the flowers were placed in the ward, they may be contaminated by the air pollution surface of the tables or beds [6]. In some studies, the concentrations of Aspergillus and Penicillium spore were much higher in the ward than outside. To examine if any pathogens can be found on the flowers in the ward, fungus cultures were taken from the different parts of flowers.

\section{Methods}

\section{Materials}

From 30th Nov 2009 to 6th Jan 2010, 10 strains of flower were randomly chosen from the visitors who brought the flowers to visit the patients in ID ward. The patients stayed in the ID ward from one week to three months. These patients were major diagnosed with unknown fever and central nervous system infection. There were 4 patients located in each room. The flowers were placed in the rooms and the windows were kept open 1 hour twice per day (AM and PM). The room temperature maintained at $18-22^{\circ} \mathrm{C}$ with humidity of $35-45 \%$.

\section{Sampling}

Each bunch of flower was taken picture. Samples were collected by sterile scissors from different parts of the flowers, such as petals, floral leaf, stems, flower roots (or mud, root nutrient solution). The sampling process was sterilized to avoid any contamination. The samples were sent to mycology laboratory with half an hour of collection. The $2^{\text {nd }}$ samples were collected from the same bunch of flower which was placed at a designated area in the ward on Day 8. Total 76 samples were collected in this study (Table 1).

\begin{tabular}{|l|l|l|l|l|}
\hline No. & Flowers & Sampling parts & \multicolumn{2}{|l|}{ Sampling amount } \\
\cline { 4 - 5 } & & & Day 1 & Day 8 \\
\hline 1 & Water lily, black-naped oriole & Flower petal, core, stem, root, nutrient solution & 5 & 5 \\
\hline
\end{tabular}


Citation: Liu J, Wang Y, Zhu L, Zhang Q, Zhang W et al. (2014) A Laboratory Study on Pathogenic Fungi Carried by Flowers in an Infectious

\begin{tabular}{|l|l|l|l|l|}
\hline 2 & Carnation, White lily, auxiliary flowers & Flower root, leaf, petal, core, stem, nutrient solution & 6 & 6 \\
\hline 3 & Water lily, baby's breath & Flower petal, core, stem, root, nutrient solution & 5 & 5 \\
\hline 4 & Water lily, baby's breath & Flower petal, core, stem, root, nutrient solution & 5 & 5 \\
\hline 5 & Water lily, black-naped oriole & Flower petal, core, stem, root, nutrient solution & 5 & 5 \\
\hline 6 & Rose & Flower petal, leaf, root, nutrient solution & 4 & 4 \\
\hline 7 & Money plant & Flower leaf, root, nutrient solution & 3 & 3 \\
\hline 8 & Water lily, black-naped oriole & Flower petal, core, leaf, stem, root, nutrient solution & 5 & 5 \\
\hline Total & & & 38 & 38 \\
\hline
\end{tabular}

Table 1: The details of flower sample collection

\section{Statistical analysis}

The data analysis was done by SPSS 13.0 software. Enumeration data were compared using chi square test or Fisher's exact test and significance was inferred for $\mathrm{P}<0.05$.

\section{Results}

Seventy-six samples were divided into 2 groups (38 samples each group) which were collected on Day 1 and Day 8. 66 of 76 (86.8\%) were pathogenic fungi positive. In the 318 positive colonies from the 66 samples, 78 were Candida (Figure 1A), 46 were dematiaceous fungi (Figure 1B), 42 were red yeast (Figure 1C), 34 were aspergilla including Aspergillus flavus, Aspergillus fumigatus and Aspergillus niger, 24 were mold fungi (Figure 1C), 18 were fusarium, 12 were Penicillium notatum and 64 underdetermined. There were no significantly difference of strain proportion of fungus cultures on day 1 and day $8\left(\chi^{2}=7.11, P>0.05\right.$; Table 2$)$. In 10 negative culture samples, 7 were collected from flower cores, 2 were from leaves and 1 was from petal.

\begin{tabular}{|l|l|l|l|}
\hline Fungi & $\begin{array}{l}\text { Positive results at Day } \\
\mathbf{1}\end{array}$ & $\begin{array}{l}\text { Positive } \\
\text { results at Day } \\
\mathbf{8}\end{array}$ & Total \\
\hline Candida & $36(46.2 \%)$ & $42(53.8 \%)$ & 78 \\
\hline $\begin{array}{l}\text { Dematiaceous } \\
\text { fungi }\end{array}$ & $25(54.3 \%)$ & $21(45.7 \%)$ & 46 \\
\hline Red yeast & $26(61.9 \%)$ & $16(38.1 \%)$ & 42 \\
\hline Aspergilla & $22(64.7 \%)$ & $12(35.3 \%)$ & 34 \\
\hline Mold fungi & $11(45.8 \%)$ & $13(54.2 \%)$ & 24 \\
\hline Fusarium & $10(55.6 \%)$ & $8(44.4 \%)$ & 18 \\
\hline Penicillium notatum & $5(41.7 \%)$ & $7(58.3 \%)$ & 12 \\
\hline Underdetermined & $29(45.3 \%)$ & $35(54.7 \%)$ & 64 \\
\hline Total & $164(51.6 \%)$ & $154(48.4 \%)$ & 318 \\
\hline
\end{tabular}

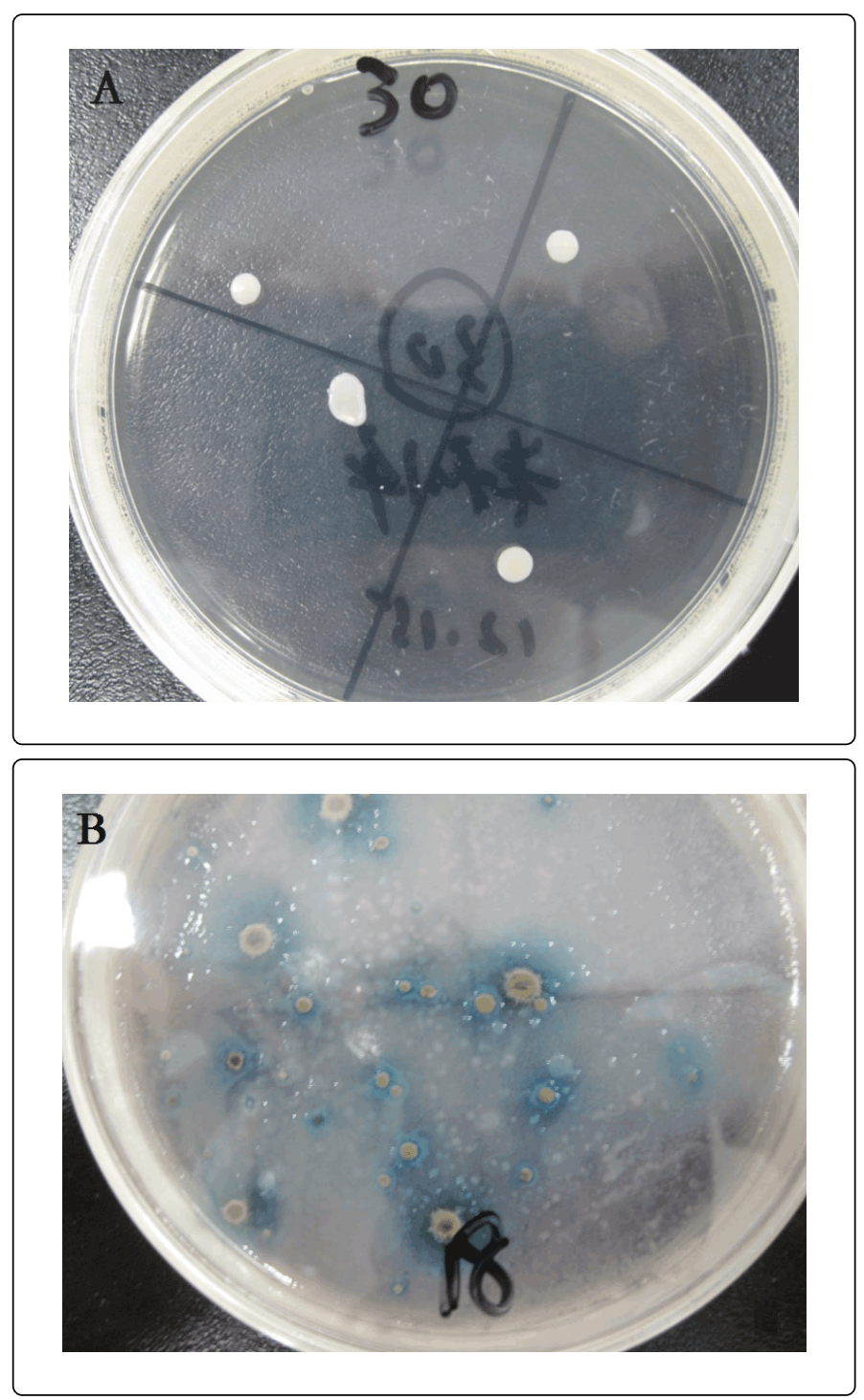

Table 2: The fungi culture results at day 1 and day 8 . 


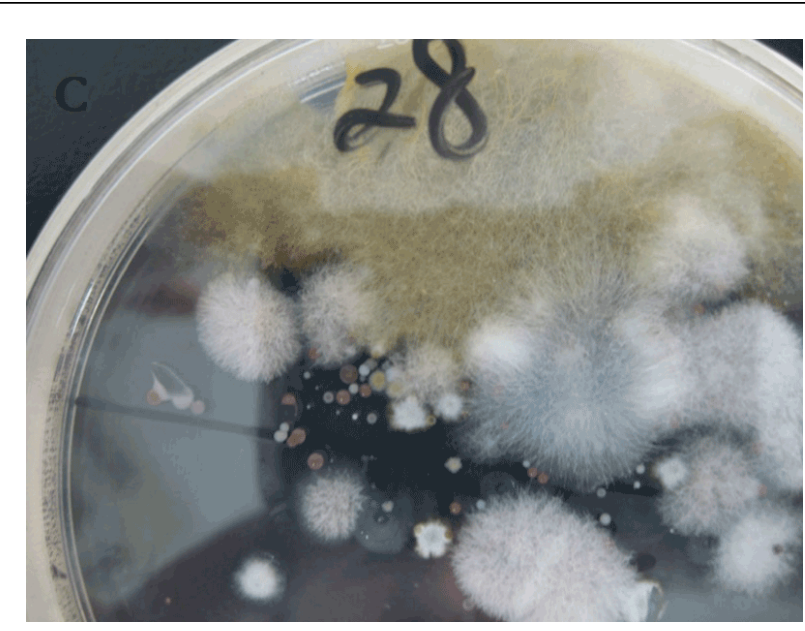

Figure 1:The positive fungal culture plates. (A) Candida of sample No. 30; (B) dematiaceous fungi of sample No. 18; (C) Penicillium notatum, mold fungi, red yeast and Candida of sample No. 20.
There were 33 paired samples among the 76 flower samples on Day 1 and Day 8. 6 pairs were consistent, 23 pairs were inconsistent $\left(\chi^{2}=38.11, \quad \mathrm{P}<0.01\right.$; Table 3$)$, and 4 pairs were pending. The proportions of culture positive of Candida were $24.6 \%$ and $35.9 \%$ on day 1 and day 8 in the paired samples. The proportions of culture positive of Candida were $24.6 \%$ and $35.9 \%$ on day 1 and day 8 in the paired samples. The proportions of culture positive of Candida were $24.6 \%$ and $35.9 \%$ at day 1 and day 8 in the paired samples. Red yeast were $21.7 \%$ and $18.0 \%$ and dematiaceous fungi were $20.3 \%$ and $15.4 \%$, respectively.

\begin{tabular}{|l|l|l|l|}
\hline Sampling time point & \multirow{2}{*}{ Samples } & \multicolumn{2}{|l|}{ Fungi culture results } \\
\cline { 3 - 5 } & & Consistent & Inconsistent \\
\hline Day 1 & 29 & 0 & 29 \\
\hline Day 8 & 29 & 23 & 6 \\
\hline
\end{tabular}

Table 3: The comparison of fungi culture results at day 1 and day 8 .

\section{Discussion}

There were limited studies and research regarding at pathogens which were carried by flowers placed in the ward in the world. This study aimed to investigate pathogenic fungi on different parts of flowers in the ward. This article could contribute for infection control especially for those suffering immunosuppressed patient group in the hospital.

In this study, 66 of $76(86.8 \%)$ were pathogenic fungus positive. The major fungus was Candida (24.5\%), dematiaceous fungi and red yeast $[7,8]$. In the 10 negative culture samples, 7 were from flower cores. It indicated that the pathogens suspended indoor air and drooped down on the surface of flowers. The predominant microorganisms including fungi and bacteria, such as staphylococcus aureus, Bacillus cereus and Acinetobacter could be detected in the indoor air in the ward such as staphylococcus aureus, Bacillus cereus and Acinetobacter could be detected in the indoor air in the wards [9]. Segvić et al found that Cladosporium, penicillium and Alternaria were common fungus which can detected in the air [10]. In addition, Lugauskas et al monitored the concentrations and distributions of fungus species and suggested that aspergillus, Cladosporium, Alternaria and Aureobasidium pullulans could be used as air pollution assessment standard [11]. The flower core was in the deep center of the flowers and it was considered as the most "clean" part of the flowers. While the samples from the stems, roots and nutrient solutions were fungus positive $100 \%$, it indicated fungus were easyto grow in the high nutritive substances.
There were similar constituent fungus between on Day 1 and Day 8. However, the results of the paired samples showed that 23 of 33 (69.7\%) fungus colonies changed when the samples at different time. It indicated the time may impact the pathogenic fungus species. It recommended the impact of the fungus species carried by flowers need further investigations.

\section{Conclusions}

The patients who received broad-spectrum antibiotics, deep venous catheterization or immunosuppressive treatment were at high risk of fungus infections in the ID ward. It is important to identify the infection sources for infection control and protect the patients from nosocomial infections [12]. It is not recommended for the vistors bring the flowers to visit the patients based on this study.

\section{Acknowledgment}

The present study was partly supported by Shanghai Science and Technology Development Funds (10QA1401100).

\section{Conflict of Interest}

The authors declare no conflicts of interest. 
Citation: Liu J, Wang Y, Zhu L, Zhang Q, Zhang W et al. (2014) A Laboratory Study on Pathogenic Fungi Carried by Flowers in an Infectious Disease Ward . J Nurs Care 3: 201. doi:10.4172/2167-1168.1000201

Page 4 of 4

\section{References}

1. Chen Y, Li J, Xing F (2005) The risk factors of environment quality in pediatric ward and the suggestions of environment improvement. Modern Nur 11: 96-97.

2. Santos E, De Oliviera R, MendonÃ§a-Hagler L, Hagler A (1996) Yeasts associated with flowers and fruits from a semi-arid region of Northeastern Brazil. Rev Microbiol 27: 33-40.

3. Vadkertiová R, Molnárová J, Vránová D, Sláviková E (2012) Yeasts and yeast-like organisms associated with fruits and blossoms of different fruit trees. Can J Microbiol 58: 1344-1352.

4. Sipiczki M (2012) Pichia bruneiensis sp. nov., a biofilm-producing dimorphic yeast species isolated from flowers in Borneo. See comment in PubMed Commons below Int J Syst Evol Microbiol 62: 3099-3104.

5. Iino T, Suzuki R, Kosako Y, Ohkuma M, Komagata K, et al. (2012) Acetobacter okinawensis sp. nov., Acetobacter papayae sp. nov., and Acetobacter persicus sp. nov.; novel acetic acid bacteria isolated from stems of sugarcane, fruits, and a flower in Japan. J Gen Appl Microbiol 58: $235-243$.
6. Tormo Molina R, Gonzalo Garijo MA, Muñoz Rodríguez AF, Silva Palacios I (2002) Pollen and spores in the air of a hospital out-patient ward. Allergol Immunopathol (Madr) 30: 232-238.

7. Tang X, Li G (2008) Treatment of aspergillosis: clinical practice guidelines of Infectious Diseases Society of America. Chin J Infect Chemother 8: 161-166.

8. Pappas PG, Rex JH, Sobel JD, Filler SG, Dismukes WE, et al. (2004) Guidelines for treatment of candidiasis. Clin Infect Dis 38: 161-189.

9. Dong Y, Jin G, Zhang Q, Wu L (2003) Air microorganisms in wards: detection and analysis. Chin J Nosocom 13: 1134-1135.

10. Segvia Klaria M, Pepeljnjak S (2006) A year-round aeromycological study in Zagreb area, Croatia. Ann Agric Environ Med 13: 55-64.

11. Lugauskas A, Sveistyte L, Ulevicius V (2003) Concentration and species diversity of airborne fungi near busy streets in Lithuanian urban areas. Ann Agric Environ Med 10: 233-239.

12. Wu X, Li X, Chen $\mathrm{H}$ et al. Risk factors of invasive fungal infection in respiratory ward: a retrospective case control study. Chin J Respir Crit Care Med 2009; 8: 544-546. 